\title{
Consumo, estética, técnica e religião em Cloaca, de Wim Delvoye
}

\section{Consumption, aesthetic, technique and religion in Wim Delvoye's Cloaca}

Icaro Ferraz Vidal Junior ${ }^{1}$

Resumo: Cloaca (2000-2010), de Wim Delvoye, consiste em um conjunto de máquinas desenvolvidas para produzir "merda real industrializada" em museus e galerias de arte. Após descrição sumária da série, desdobramos nossa análise em três eixos: o primeiro baseado na articulação psicanalítica entre merda e dinheiro; o segundo na diferenciação formulada geneticamente por Gilbert Simondon (1989) entre estética, técnica e religião; e o terceiro no conceito de máquina, formulado por Gilles Deleuze e Félix Guattari (1972). Por fim, comparamos Cloaca e Anal Kisses (2011), projeto do mesmo artista, e buscamos identificar alguns vetores culturais que incidiram na recepção desigual dos dois projetos.

Palavras-chave: consumo; analidade; técnica; arte contemporânea; Wim Delvoye.

\begin{abstract}
Cloaca (2000-2010), by Wim Delvoye, consists of a set of machines developed in order to produce "real industrialized shit" in Museums and Art Galleries. After a brief description of the series, we unfold our analysis on three axes: the first one is based on the psychoanalytical articulation between shit and money; the second one on the differentiation genetically formulated by Gilbert Simondon (1989) between aesthetics, technics and religion; the third one on the concept of machine, formulated by Gilles Deleuze and Félix Guattari (1972). Finally, we compare Cloaca and Anal Kisses (2011), a project by the same artist, in an attempt to identify some cultural vectors that affected the uneven reception of both projects.
\end{abstract}

Keywords: consumption; anality; technique; contemporary art; Wim Delvoye.

1 Pontifícia Universidade Católica de São Paulo (PUC-SP). São Paulo, SP, Brasil.

https://orcid.org/0000-0003-4907-1267 E-mail: vidal.icaro@gmail.com 


\section{A série}

O projeto Cloaca, do artista belga Wim Delvoye, consistiu em um conjunto de máquinas produzidas entre 2000 e 2010, após mais de dez anos de pesquisa do artista com cientistas de várias disciplinas. Endossando o argumento de Isabelle Wallace (2011), parece-nos fundamental considerar Cloaca como uma série. A atenção dispensada ao design e à logomarca de cada versão da máquina foi um aspecto central no desenvolvimento do projeto, através do qual o modo de produção pós-industrial adquiriu o estatuto de linguagem. Embora Cloaca culmine em máquinas de feições industriais; ao olharmos para a série, constatamos que o processo de produção de valor paralelo ao desenvolvimento das diversas versões da máquina concentrou-se nestes dois aspectos: design e branding.

Wallace apresenta o projeto nos seguintes termos:

Descrito pelo artista como uma "máquina de merda", Cloaca Original, 2000, como as sete obras que a sucederam rapidamente, é simplesmente isso: uma máquina computadorizada concebida com o objetivo de fabricar merda real, feita à máquina, no contexto aberto da galeria de arte ou do museu (WALLACE, 2011, p. 217, todas as traduções são nossas).

As máquinas de Delvoye recebem alimentos duas vezes por dia. Essas refeições percorrem vários recipientes através dos quais são submetidas a processos mecânicos e ao contato com substâncias químicas que mimetizam as excretadas em nosso sistema digestivo. A merda sintética expelida ao fim deste percurso preserva uma inquietante semelhança com os excrementos humanos. O produto destas máquinas é amplamente responsável pela repercussão de Cloaca, mas não podemos negligenciar que o próprio maquinário é extremamente sedutor, e que as escolhas estéticas que se encontram em sua origem desempenham papel crucial nesta sedução. Se analisássemos apenas Cloaca Original, provavelmente hiperdimensionaríamos a virtuose técnica da instalação. Mas ao olharmos para o conjunto das máquinas produzidas entre 2000 e 2010, conseguimos observar a separação entre forma e função, operada 
pelo artista na contramão do produtivismo e da eficácia industriais. O design da máquina varia a cada nova versão, ao passo que sua função permanece a mesma: produzir merda.

Essa duplicação paródica de procedimentos do marketing aparece no ensaio de Wallace, quando ela compara as duas primeiras máquinas da série:

Como se poderia esperar pelo seu título, Cloaca New E Improved é similar à primeira máquina, embora acompanhando a trajetória da série como um todo, Cloaca New \& Improved é mais compacta e aparentemente mais high-tech. Enquanto a estética de Cloaca Original lembra um projeto científico abertamente ambicioso, Cloaca New E Improved tem um design mais elegante, industrial, suas partes negligenciáveis (tubos, fios etc.) elegantemente guardadas em vitrines quadradas de aço inoxidável que escondem, mais do que confessam, os detalhes do processo. Mesmo assim, a produção da primeira e da segunda máquina é essencialmente a mesma: como sua predecessora, Cloaca New \& Improved produz entre 200 e 400 gramas de merda a cada dia no mesmo momento (WALLACE, 2011, p. 218).

O desenvolvimento da série testemunha a consciência do artista acerca do fato de que o design e o marketing teriam se convertido, à nossa época, em linguagem. Depois de Cloaca Original (Figuras 1 e 2), cuja logomarca mistura a elipse azul da Ford e a tipografia da Coca-Cola; Cloaca New \& Improved (Figuras 3 e 4) acrescenta a essas duas referências icônicas a imagem de Mr. Clean - o personagem da Procter \& Gamble -, com seu intestino exposto na parte inferior da imagem.

Figura 1 - Cloaca Original, 2000.

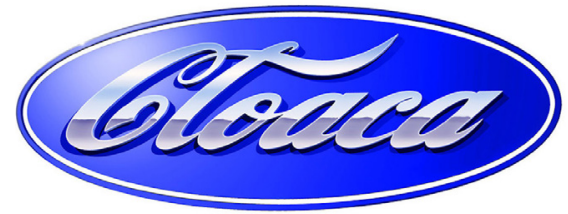

Fonte: <https://bit.ly/2GyxV0H>. Acesso em: 9 abr. 2019. 
Figura 2 - Cloaca Original, 2000, Museum Kunst Palast, Düsseldorf, 2001.

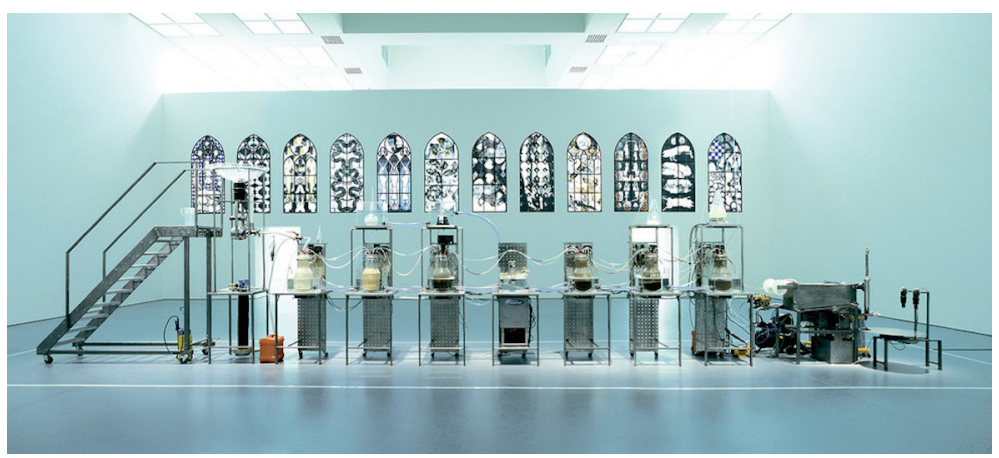

Fonte: <https://bit.ly/2GyxV0H>. Acesso em: 9 abr. 2019.

Figura 3 - Cloaca New E Improved, 2001.

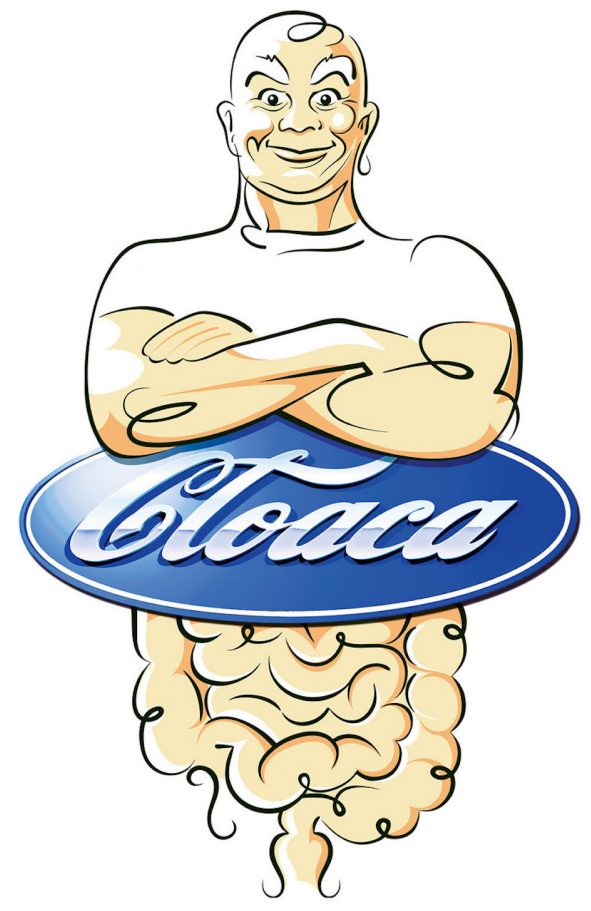

Fonte: $<$ https://bit.ly/2GttYKs $>$. Acesso em: 9 abr. 2019. 
Figura 4 - Cloaca New E Improved, 2001, Ernst Museum, Budapeste, 2008.

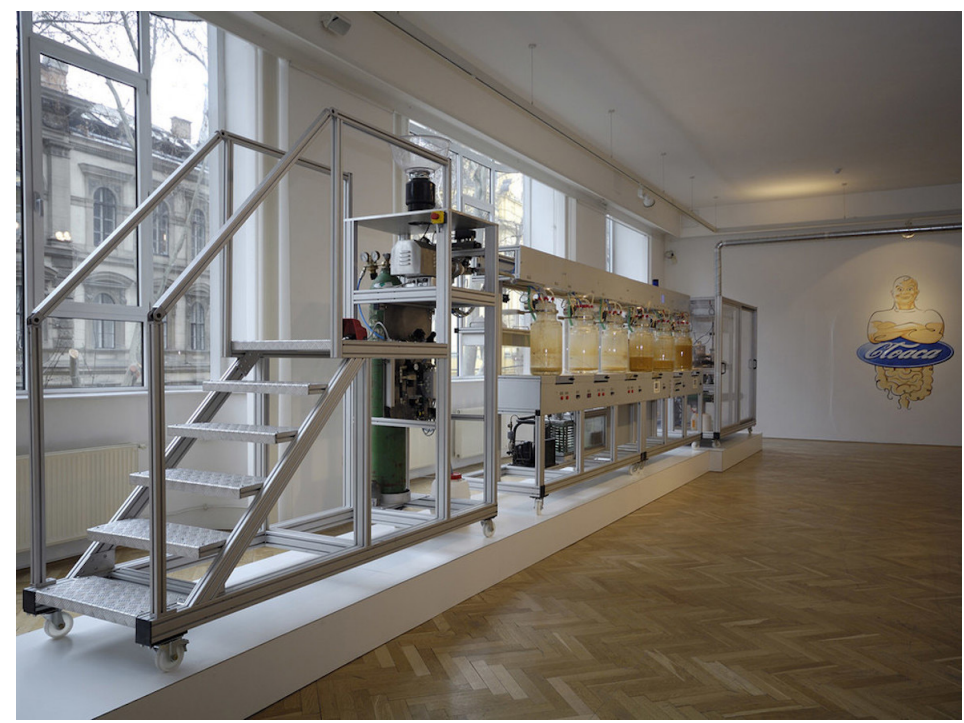

Fonte: <https://bit.ly/2GttYKs>. Acesso em: 9 abr. 2019.

Um intestino também aparece no interior de um brasão, na logomarca de Cloaca Turbo (Figuras 5 e 6), que parodia a marca Harley Davidson e nos lembra de que os brasões, emblemas distintivos de nobres e de militares, fazem parte da genealogia deste modo curioso através do qual logomarcas de empresas multinacionais tornaram-se partes fundamentais do repertório de signos a partir do qual nos subjetivamos contemporaneamente. O design de Cloaca Turbo, de 2003, segue em linhas gerais o design de Cloaca New \& Improved, mas introduz, no lugar dos seis recipientes cilíndricos de vidro, três máquinas de lavar, destacando o órgão mecânico que dá título a esta edição da máquina e que se define pela grande velocidade de rotação. 
Figura 5 - Cloaca Turbo, 2003.

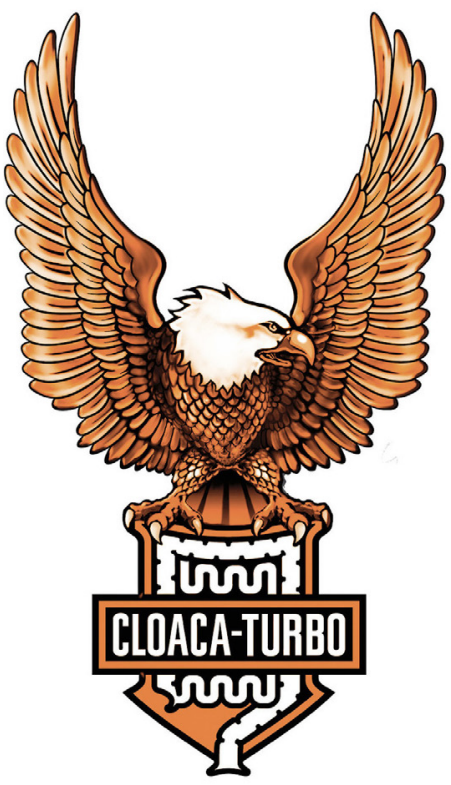

Fonte: <https://bit.ly/2WUmsfO >. Acesso em: 9 abr. 2019.

Figura 6 - Cloaca Turbo, 2003, CAPC, Bordeaux, 2004-2005.

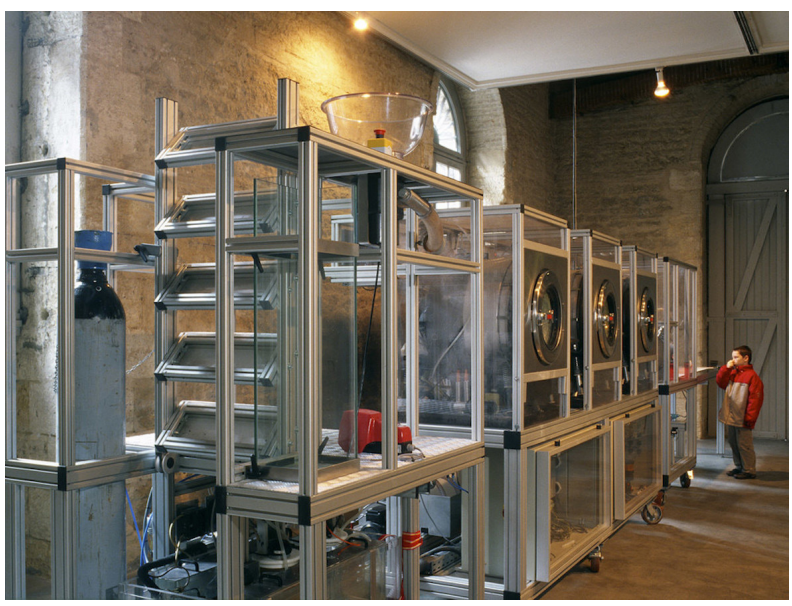

Fonte: <https://bit.ly/2WUmsfO>. Acesso em: 9 abr. 2019. 
Os compartimentos do tipo máquina de lavar também estão presentes na quarta versão da máquina (Figuras 7 e 8), de 2004-2005, cuja logomarca apresenta, mais uma vez, a imagem de Mr. Clean, mas desta vez sem a elipse da Ford. A verticalidade do antropomórfico Mr. Clean é mimetizada pela máquina, que apresenta dois compartimentos superpostos e a saída pela qual o excremento sintético é evacuado em sua parte inferior. Esta verticalidade, cara a nós, bípedes, é também explorada em Cloaca $\mathrm{N}^{\circ} 5$ (Figuras 9 e 10), cujo design mais elegante condiz com sua logomarca, uma paródia da marca de perfume Chanel $\mathrm{N}^{0} 5$, que tem sua proveniência parisiense substituída pela China, enfatizando o processo de offshoring. Este fenômeno, caro ao reordenamento geopolítico do trabalho, marca a própria trajetória do artista que, impedido de tatuar porcos na Bélgica no âmbito de outro controverso projeto, mudou-se para a China.

Figura 7 - Cloaca Quattro, 2004-2005.

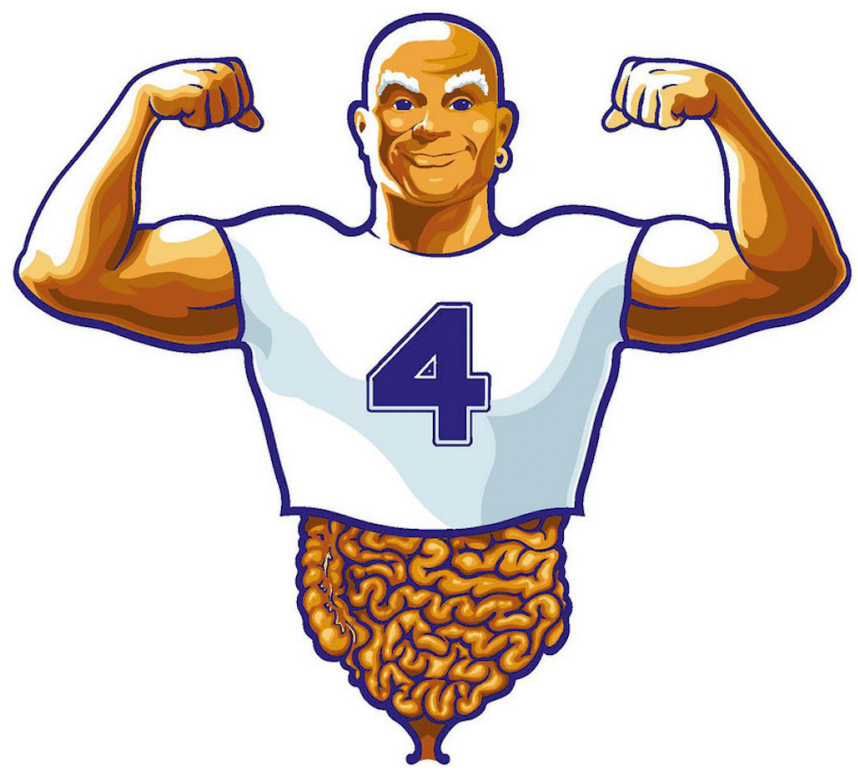

Fonte: <https://bit.ly/2EeBRRC>. Acesso em: 9 abr. 2019. 
Figura 8 - Cloaca Quattro, 2004-2005, BOZAR, Bruxelas, 2005.

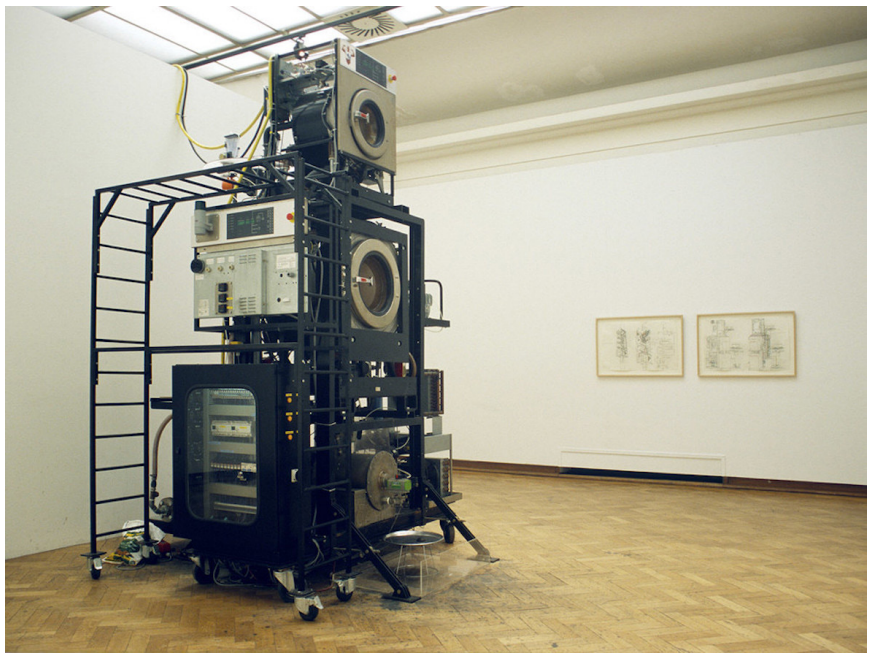

Fonte: $<$ https://bit.ly/2EeBRRC $>$. Acesso em: 9 abr. 2019.

Figura 9 - Cloaca N ${ }^{\circ}$ 5, 2006.

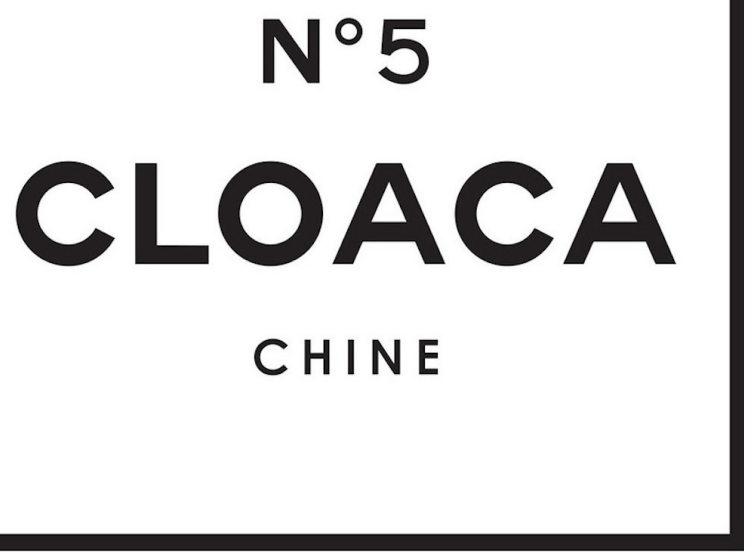

Fonte: <https://bit.ly/2TRxpxF>. Acesso em: 9 abr. 2019. 
Figura 10 - Cloaca Nº 5, 2006, Glenbow Museum, Calgary, 2008.

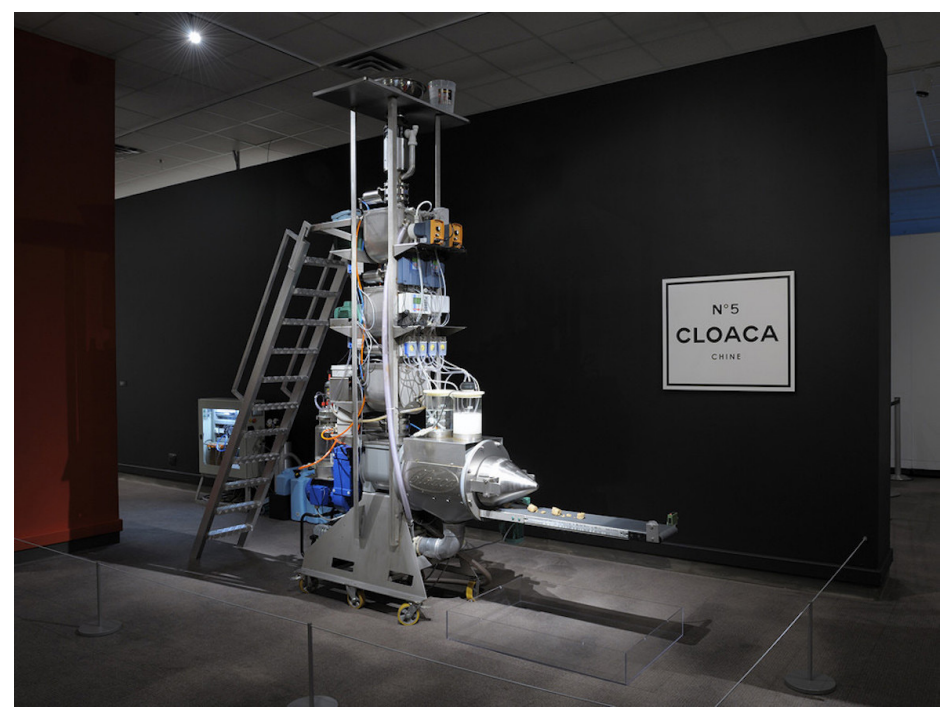

Fonte: <https://bit.ly/2TRxpxF>. Acesso em: 9 abr. 2019.

Outras tendências que marcam o desenvolvimento tecnológico em nossa época são exploradas a partir da sexta versão de Cloaca, intitulada Personal Cloaca (Figuras 11 e 12). Esta versão, de tamanho mais modesto, consiste em uma máquina de lavar que recebe as refeições por um compartimento situado em sua parte superior e defeca por um tubo situado em sua parte inferior. Sua logomarca, criada a partir da marca de preservativos Durex, evoca relações mais íntimas com a máquina, em escala doméstica. Delvoye reproduz, assim, o processo através do qual máquinas de dimensões monumentais e custo exorbitante, tornam-se, com o passar dos anos, objetos de uso pessoal. 
Figura 11 - Personal Cloaca, 2006.

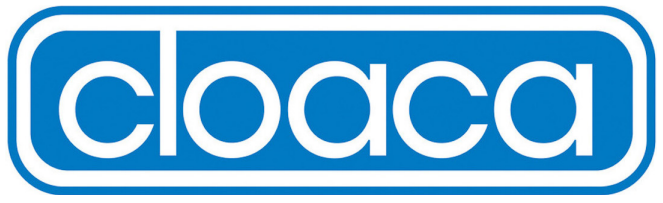

Fonte: <https://bit.ly/2ST4xrA>. Acesso em: 9 abr. 2019.

Figura 12 - Personal Cloaca, 2006, Marta Herford, Herford, 2008.

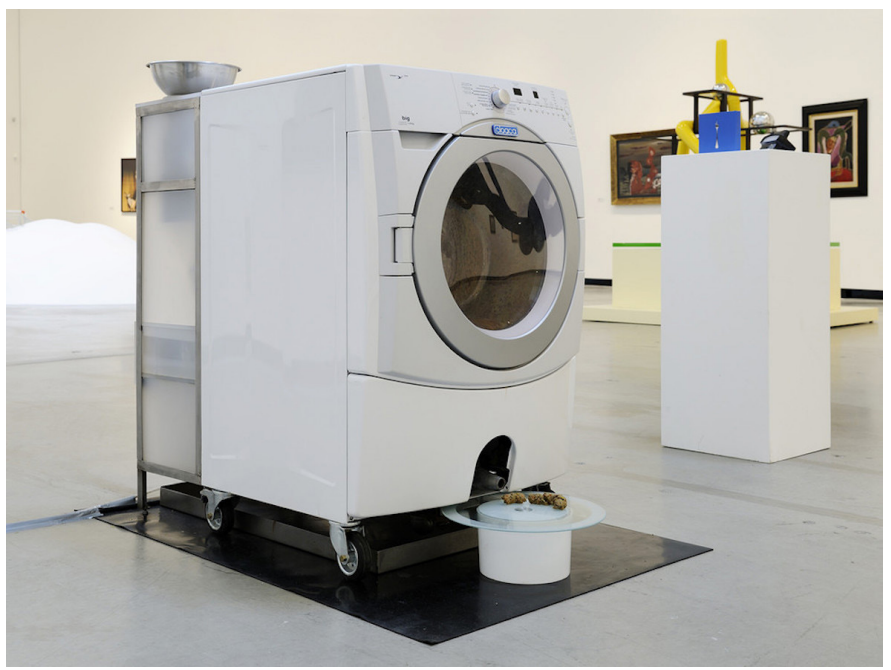

Fonte: <https://bit.ly/2ST4xrA>. Acesso em: 9 abr. 2019.

Um ano após a produção de Personal Cloaca, Delvoye produz Super Cloaca (Figuras 13 e 14) que retoma a grande escala, mas, desta vez, em uma relação de proporcionalidade com a eficácia produtiva. Em vez de produzir os modestos 200g-400g de excremento, Super Cloaca produz quilos e quilos de merda. Sua logomarca sobrepõe o nome Cloaca, escrito com a tipografia da Coca-Cola, ao emblema do Super-Homem, em clara alusão à sociedade de consumo norte-americana. Esta alusão é reiterada pelas roupas vestidas pelos performers que manipulam a máquina, claramente inspiradas nos uniformes de funcionários de redes de fast-food. 
Sobre uma mesa, Mini Cloaca (Figuras 15 e 16), de 2007, também explora a questão da escala. Em contraste com a Super Cloaca, Mini Cloaca só pode ingerir pequenas refeições, por isso sua logomarca retoma o design de Chiquita Banana, transformado pela inserção do rosto de Mr. Clean no lugar da personagem com frutas na cabeça, inspirada em Carmen Miranda, presente na versão original da marca.

Figura 13 - Super Cloaca, 2007.

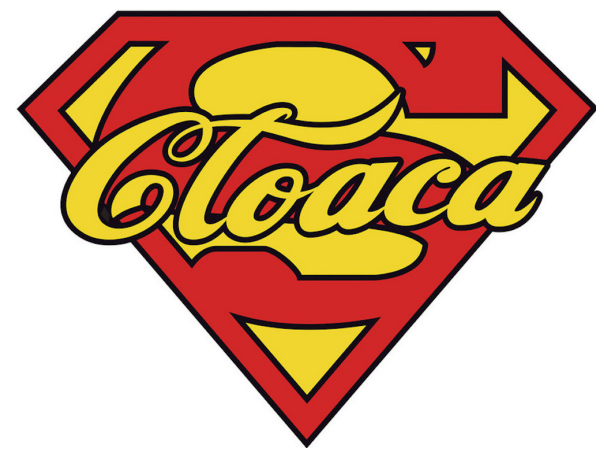

Fonte: <https://bit.ly/2N8jJM6>. Acesso em: 9 abr. 2019.

Figura 14 - Super Cloaca, 2007, MUDAM, Luxemburgo, 2007-2008.

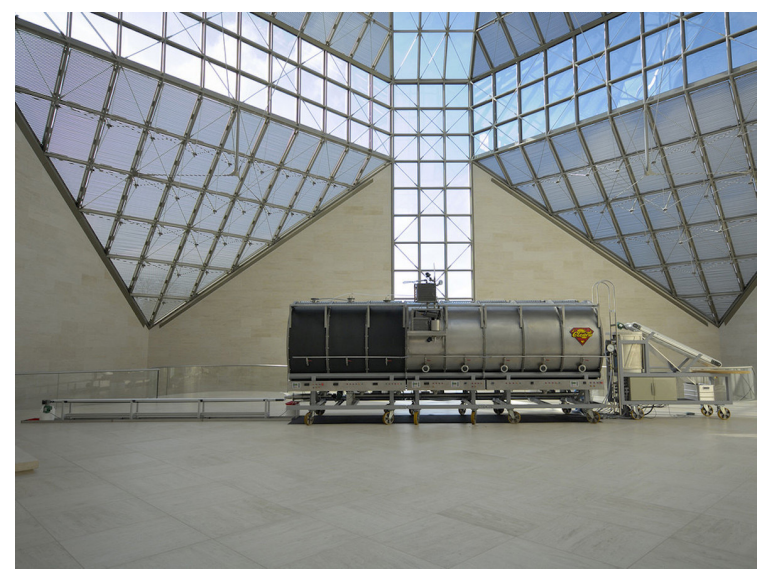

Fonte: <https://bit.ly/2N8jJM6>. Acesso em: 9 abr. 2019. 
Figura 15 - Mini Cloaca, 2007.

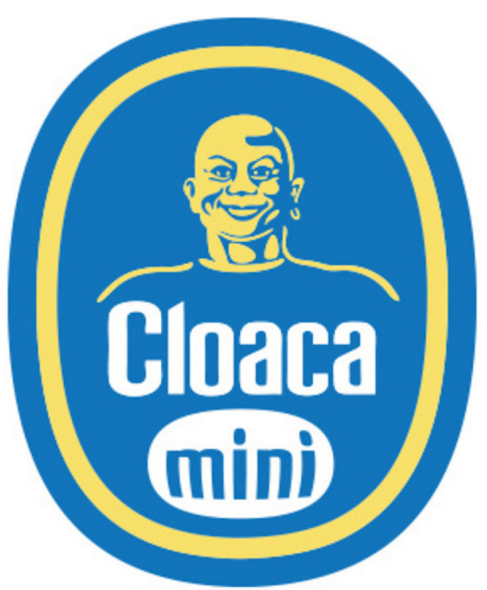

Fonte: <https://bit.ly/2Id6Gds>. Acesso em: 9 abr. 2019.

Figura 16 - Mini Cloaca, 2007, Casino Luxembourg, Luxemburgo, 2007-2008.

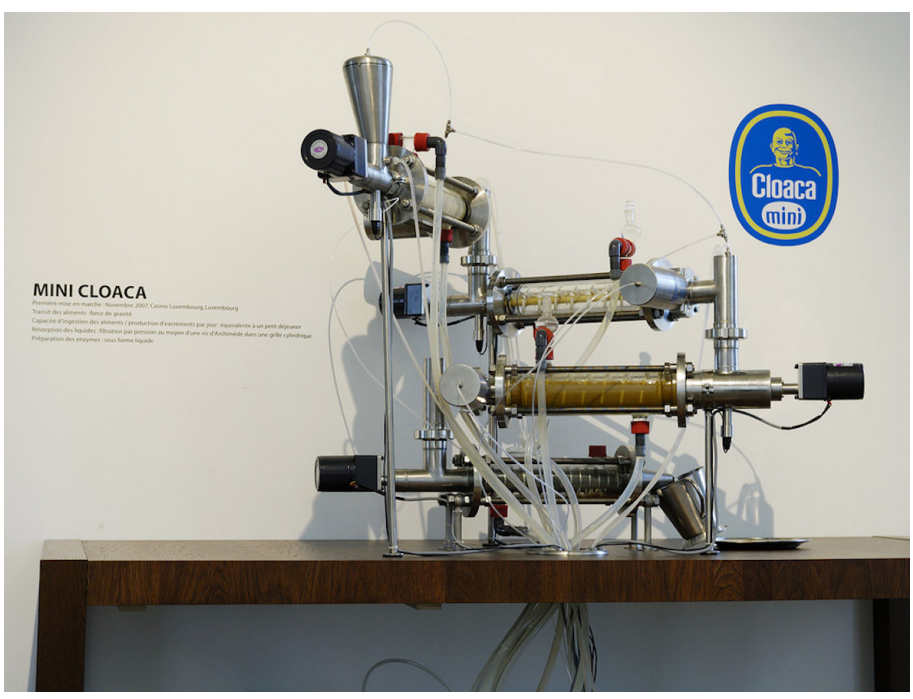

Fonte: <https://bit.ly/2Id6Gds>. Acesso em: 9 abr. 2019. 
As duas últimas versões da máquina, produzidas em 2009-2010, abordam a segmentação dos mercados consumidores. Cloaca Travel Kit (Figuras 17 e 18), como o título indica, consiste na instalação da máquina dentro de uma mala de viagem. Deste modo, Cloaca torna-se portátil. A logomarca de Cloaca Travel Kit se apropria do grafismo presente na logo da Montblanc. Cloaca Professional (Figuras 19 e 20), última máquina da série, apresenta um design que evoca o domínio de alta tecnologia. Já não se trata aqui de um design como aquele da Cloaca Original, relacionado ao imaginário da experimentação científico-industrial de inventores pioneiros. Cloaca Professional incarna as alianças entre desenvolvimento científico e tecnológico. Seu design preserva a estrutura linear horizontal mais frequentemente associada à produção industrial, mas a depuração de suas formas talvez evoque a indústria farmacêutica ou as novas tecnologias de tratamento médico. A logomarca de Cloaca Professional é composta por uma tipografia elegante e serifada, e por uma imagem quase abstrata que evoca os ossos da pélvis.

Figura 17 - Cloaca Travel Kit, 2009-2010.

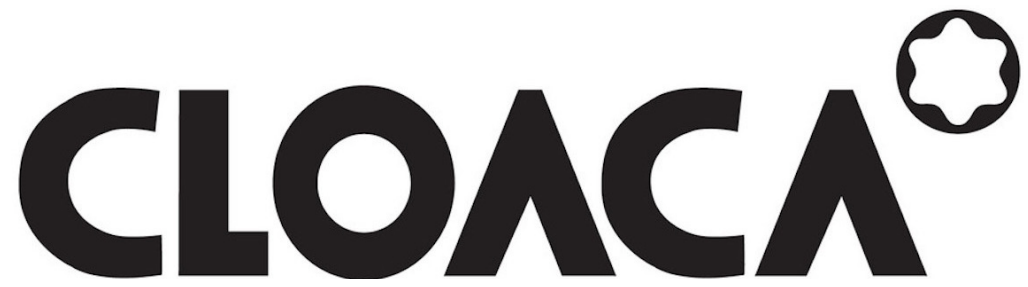

Fonte: <https://bit.ly/2S4UPOs>. Acesso em: 9 abr. 2019. 
Figura 18 - Cloaca Travel Kit, 2009-2010, Pushkin State Museum, Moscou, 2014.

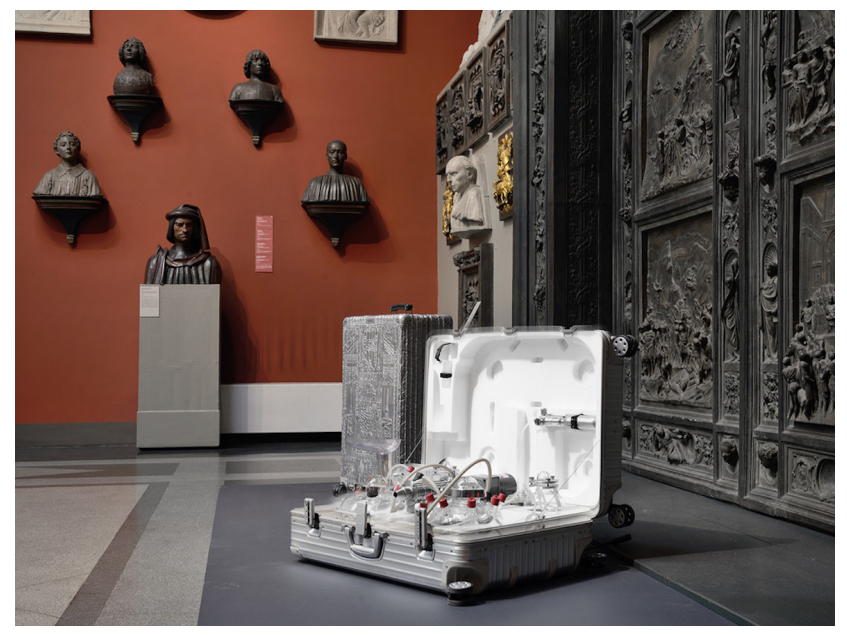

Fonte: <https://bit.ly/2S4UPOs>. Acesso em: 9 abr. 2019.

Figura 19 - Cloaca Professional, 2010.

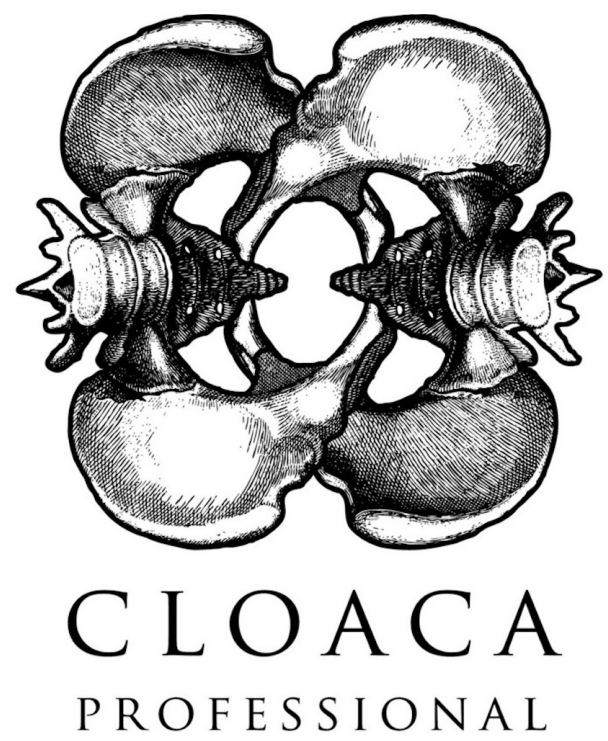

Fonte: <https://bit.ly/2EfydHr>. Acesso em: 9 abr. 2019. 
Figura 20 - Cloaca Professional, 2010, MONA, Hobart, coleção permanente.

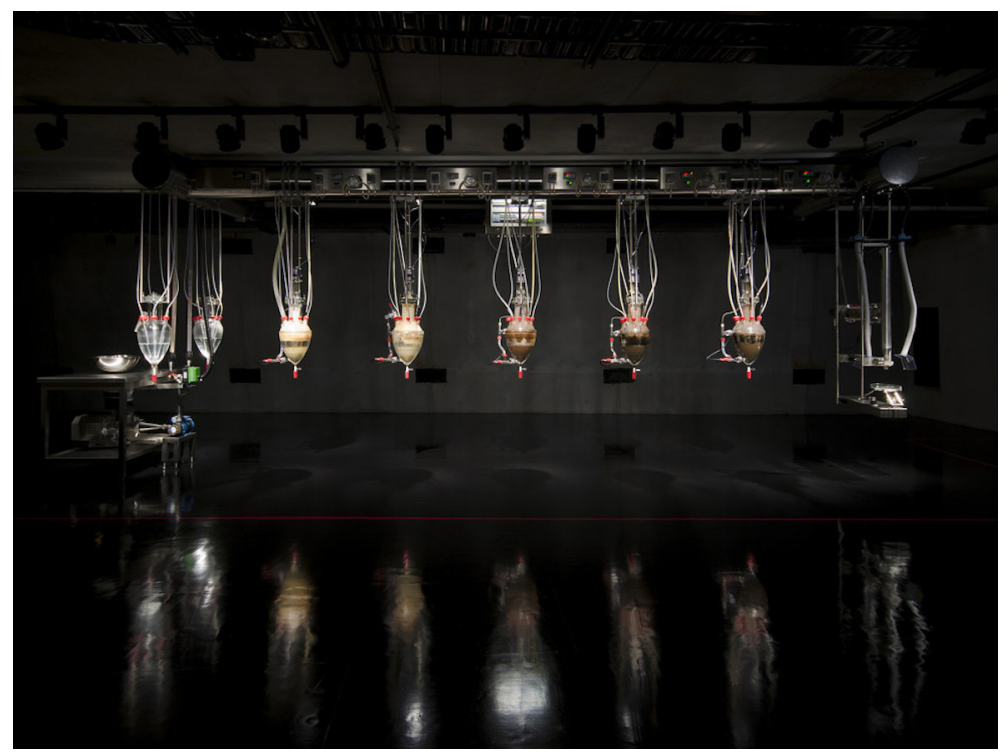

Fonte: <https://bit.ly/2EfydHr>. Acesso em: 9 abr. 2019.

\section{Merda e valor}

A respeito de Cloaca Professional, o site The Conversation, especializado em divulgação científica, publicou um artigo de Kate Patterson, especialista nas relações entre ciência e arte, no qual a autora descreve sua experiência com a obra:

Nas profundezas do icônico MONA eu estava animada para ver Cloaca Professional em primeira mão. A sala estava mais quieta do que eu imaginei, e muito, muito calma. Disseram-me que a defecação estava programada para ocorrer às $14 \mathrm{~h}$ e eu cheguei vários minutos antes [...]. Obviamente, outros tinham tido o mesmo pensamento porque já havia vários pequenos grupos de pessoas esperando quando eu cheguei. Alguns tinham os braços cruzados, parecendo na defensiva enquanto outros permaneciam de pé deslocando o próprio peso de um pé para o outro, não querendo estar presente mais tempo do que o absolutamente necessário. Ocasionalmente alguém sussurrava alguma coisa inaudível ou deixava 
escapar uma bufada constrangida. Muitos seguravam o nariz, claramente ofendidos pelo odor inevitável. Todo mundo assistia e esperava. Na hora, nós, estranhos, estávamos unidos na antecipação. Então, sem anúncio, o receptáculo fecal começou a se mover, em um movimento circular, pronto a receber o depósito da máquina. Daí, em uma suave ação como a das máquinas de sorvete, o movimento aconteceu. O receptáculo então parou, e as pessoas saíram rapidamente. Trabalho feito (PATTERSON, 2016).

O breve artigo de Patterson documenta particularmente bem uma dimensão de Cloaca que é difícil acessar: a experiência do público, que se relaciona com o projeto de modo ambíguo. Ao mesmo tempo em que há uma rejeição à produção da máquina, experimentada no registro da abjeção (KRISTEVA, 1982), observamos uma vontade de ver, modulada por afetos que são descritos com alguma suspeita pela crítica da arte e pela teoria estética contemporânea. Jacques Rancière, por exemplo, articula dois afetos, a atenção e a curiosidade - aos quais atribui um potencial emancipatório -, a uma impossibilidade de antecipação do visível e do pensável. Tais afetos apontariam, deste modo, na direção de novas políticas do sensível - "uma política baseada na variação de distância, na resistência do visível e na incerteza dos efeitos" (RANCIÈRE, 2009, p. 105). A questão, portanto, consiste em saber se a ampla midiatização e o automatismo pontual de Cloaca não acabam por reduzir essa vontade de ver a um olhar que espera e acompanha o desdobrar dos acontecimentos apenas para confirmar aquilo que já se sabe que virá, impedindo que a curiosidade se instale e se desdobre em uma experiência marcada por incerteza e indeterminação.

A descrição de Patterson testemunha, em algum nível, a complexidade das relações estabelecidas com a máquina de Delvoye. Ao fim de seu artigo, ela destaca um fato que, a despeito de sua previsibilidade, não deixa de ser curioso: "Cloaca Professional é aparentemente a exposição mais detestada do MONA, no entanto, ela é também a obra com a qual as pessoas passaram mais tempo. É este conflito que fornece uma enorme oportunidade para o debate público" (PATTERSON, 2016). 
Nosso objetivo neste artigo não será psicanalisar este público. No entanto, é difícil negligenciar o fato de que o repertório teórico proveniente da psicanálise tenha se tornado incontornável, do ponto de vista cultural, na abordagem das relações com a excreção e com a analidade no interior daquilo que aparece em Freud (1934) com o nome de civilização. Considerando algumas ideias caras ao pai da psicanálise, observamos um duplo movimento da parte de Delvoye. Por um lado, ele coloca em evidência as relações econômicas que encontraram as fontes de seu desenvolvimento no recalque das relações erógenas anais no curso do processo de genitalização da sexualidade, através do qual o erotismo anal pôde se transformar no caráter anal (FREUD, 1928). O aspecto econômico associado ao recalque do erotismo anal resulta do processo de realocação das pulsões sexuais que configuram o desenvolvimento psíquico de um sujeito. Segundo Freud (1928), o interesse pelos excrementos caro às crianças continua na fase adulta, mas ele investe novos objetos: se transforma, por um lado, no interesse pelo dinheiro, por outro, no desejo de ter um filho.

Para além deste quadro psicanalítico, é fundamental observar que o dinheiro, como o excremento, é sempre um excesso, um outro cuja alteridade nunca conseguimos suprimir. Afinal, o que é a merda? É tudo aquilo que, da minha alimentação, não consigo transformar em meu corpo. O dinheiro não possui um modo de existência muito diferente. Ele, em si mesmo, permanece inassimilável. Uma longa história foi necessária até que pudéssemos contar com um sistema de trocas cuja abundância de mercadorias e de serviços tornasse interessante a ideia de guardar dinheiro para que ele nunca falte. Em uma sociedade com um sistema de trocas rudimentar, poderíamos morrer de fome com os cofres cheios.

Por outro lado, através da tecnologia e da arte, Delvoye acaba por sublimar a experiência excretora tal como ela é vivida física e psiquicamente pelos sujeitos. Apesar da dimensão fortemente simbólica da psicanálise, podemos observar que Freud - embora negligencie o odor das fezes nas relações erógenas que a criança estabelece com elas e com seus órgãos 
excretores - aborda a excreção desde uma perspectiva que considera sua materialidade:

O bolo fecal - ou o bastão de excrementos, seguindo a expressão de um paciente - é, por assim dizer, o primeiro pênis; ele excita uma mucosa: a do reto. Há pessoas em que o erotismo anal permanece forte e intacto até a idade pré-púbere (dez a doze anos); essas pessoas nos ensinam que, desde a fase pré-genital, elas constituíam, nos fantasmas ou nos jogos perversos, uma organização análoga àquela da fase genital, o pênis e a vagina sendo apenas substituídos respectivamente pelo bolo fecal e pelo reto (FREUD, 1928, p. 614, grifo nosso).

O pano de fundo cultural evocado por Freud quando formula suas clássicas analogias entre dinheiro e excremento reaparece, subvertido, no cerne do projeto de Delvoye. Isto se dá porque o artista introduz os excrementos em outro sistema, cujo funcionamento já não se articula cultural e psiquicamente em torno da retenção e do acúmulo, mas do consumo e, até mesmo, de certo desperdício. Ao longo do século XX, as relações entre excremento e dinheiro foram retomadas e reformuladas em diversos domínios. Georges Bataille evocou essas relações para problematizar o princípio de utilidade como eixo organizador da economia.

Não basta que as jóias sejam belas e deslumbrantes, o que tornaria possível sua substituição por falsificações: o sacrifício de uma fortuna à qual preferimos uma cascata de diamantes é necessária à constituição do caráter fascinante desta cascata. Este fato deve ser relacionado ao valor simbólico das joias, geral na psicanálise. Quando um diamante tem, em um sonho, uma significação excremental, não se trata somente de associação por contraste: no inconsciente, as joias como os excrementos são os materiais malditos que escorrem de uma ferida, as partes de si destinadas a um sacrifício ostensivo (eles servem, de fato, como presentes suntuosos carregados de amor sexual). O caráter funcional das joias exige seu imenso valor material e explica sozinho o pouco caso feito das mais belas imitações, que são praticamente inutilizáveis (BATAILLE, 1970, p. 305-306).

A radicalidade de Cloaca consiste na exploração de uma matéria cuja ausência de valor de uso parece ser socialmente consensual. Se é 
verdade que não podemos supor que os excrementos não têm, de fato, valor de uso, pois, como lembra Dominique Laporte (2000), eles foram fertilizantes fundamentais para o desenvolvimento da agricultura; somos forçados a constatar que esta propriedade foi amplamente recalcada por nossa cultura.

A dimensão simbólica da merda é deslocada na instalação de Delvoye na medida em que este signo - que é a coisa mesma (PROSS, 1980, p. 14) -, cuja produção dependia do corpo e desempenhava um papel central no estabelecimento dos limites entre o sujeito e seu outro, é transformado em símbolo de falta de sentido e utilidade. A desproporção entre o nível das pesquisas científicas e dos investimentos que se encontram na base do projeto e seu resultado prático depende desta falta de sentido socialmente atribuída à matéria fecal. Apesar do desenvolvimento, no nível do design e da comunicação visual, de uma versão da máquina à versão seguinte, elas possuem, todas, este mesmo e perturbador objetivo: produzir merda. O consenso em torno da falta de valor da merda permite a Delvoye empregá-la para ativar um dispositivo que se apresenta como alegoria da falência teleológica da sociedade de consumo.

Mas o gesto de Delvoye não investe apenas na devoração do sistema da arte pelo capitalismo de consumo; aborda também aspectos tangenciais a esses dois campos. Por exemplo, através de reflexões em torno das relações entre ciência e religião, ou dos limites do que consideramos, por ora, próprio ao humano.

\section{Estética, técnica e religião}

Um dos caminhos abertos pelo projeto de Delvoye permite reivindicar a delegação da produção de excrementos às máquinas na chave do que chamaremos de hipótese pós-humanista, que enfatiza a obsolescência do corpo humano em face dos desenvolvimentos técnicos. Se não há nada de absurdo nesta hipótese, ela parece cair, algumas vezes, em um excesso retórico ao qual aderimos muito rapidamente. Duas perspectivas nos ajudarão a revisar esta hipótese: a primeira é sistematizada por Gilbert Simondon em Do modo de existência dos objetos técnicos; a segunda é 
formulada por Gilles Deleuze e Félix Guattari em O anti-Édipo: capitalismo e esquizofrenia 1 , notadamente através do conceito de máquina.

Em relação ao livro de Simondon, o que nos ajuda a pensar Cloaca para além de uma tecnofobia humanista e de uma tecnofilia pós-humanista é a revisão, através do conceito de tecnicidade, da lógica que opõe a cultura à técnica e o homem à máquina.

A cultura é desequilibrada porque ela reconhece alguns objetos, como o objeto estético, e lhe confere direito à cidade no mundo das significações, enquanto ela recalca outros objetos, e em particular os objetos técnicos, no mundo sem estrutura do que não possui significação, mas somente um uso, uma função útil. Diante desta recusa defensiva, pronunciada por uma cultura parcial, os homens que conhecem os objetos técnicos e sentem sua significação procuram justificar seu julgamento dando ao objeto técnico o único estatuto atualmente valorizado fora daquele do objeto estético, o de objeto sagrado (SIMONDON, 1989, p. 10).

Chama atenção, no trecho acima, a categorização por Simondon de três tipos de objeto: o técnico, o estético e o sagrado. Adiante, na mesma obra, a ontogênese desses três modos de existência é descrita por Simondon nos termos de uma defasagem "de um modo único, central e original de ser no mundo, o modo mágico" (SIMONDON, 1989, p. 160). Dessa defasagem emergem dois outros modos de ser no mundo: o modo técnico e o modo religioso. Entre essas duas novas fases - técnica e religiosa - encontra-se, destituído do estatuto de fase, o objeto estético, cujo modo de existência é caracterizado pela remissão à unidade originária perdida, da qual derivaram técnica e religião. Nas palavras do filósofo:

A unidade mágica primitiva é a relação de ligação vital entre o homem e o mundo, definindo um universo ao mesmo tempo subjetivo e objetivo anterior a toda distinção do objeto e do sujeito, e consequentemente também a toda aparição do objeto separado. Podemos conceber o modo primitivo de relação entre o homem e o mundo como anterior não somente à objetivação do mundo, mas também à segregação de unidades objetivas no campo que será o campo objetivo. É a um universo experimentado como meio que o homem se encontra ligado. A aparição do objeto não 
se faz senão pelo isolamento e pela fragmentação da mediação entre o homem e o mundo; e, segundo o princípio colocado, essa objetivação de uma mediação deve ter por correlativo, em relação ao centro neutro primitivo, a subjetivação de uma mediação; a mediação entre o homem e o mundo se objetiva em objeto técnico como ela se subjetiva em mediador religioso (SIMONDON, 1989, p. 163-164).

Cloaca mobiliza dois domínios que, segundo Freud e Simondon, respectivamente, foram recalcados pela cultura: o da excreção e o do objeto técnico. Esses dois campos partilham uma operação de objetivação, ligada à ruptura de uma unidade originária que, em Freud, assume a forma do estádio pré-civilizado da criança e, em Simondon, a do modo de existência mágico do mundo, anterior ao surgimento, por defasagem, da técnica e da religião. Desse modo, Cloaca instaura um terceiro corte, que exterioriza, autonomiza e automatiza o processo digestivo, e cria um eixo que complexifica o esquema simondoniano, na medida em que os objetos técnicos que compõem a série poderiam, em função de escolhas de Delvoye, mas também de contingências históricas, ser pensados como objetos sagrados e/ou objetos estéticos.

No texto de Freud (1928), o ponto de vista dos pais que esperam pelos excrementos da criança não é um objeto de análise. Quando observamos Cloaca, isto ganha relevância na medida em que a posição que assumimos no dispositivo de Delvoye não é a da criança que sacrifica (ou não) uma parte de si como presente para os pais, mas a dos pais à espera deste presente. E este lugar de espera, ao mesmo tempo confortável e destituído de potência, parece ser também ocupado por nós em nossas relações, frequentemente alienadas, com os objetos técnicos.

Se à técnica corresponde uma objetivação do mundo, o correlato subjetivo deste processo encontra-se, segundo Simondon, na religião. No universo de Delvoye, essas duas fases serão tensionadas até que o pertencimento dos objetos instalados no espaço expositivo a um ou outro modo de existência beire o indecidível. Não é por acaso que as grandes máquinas que compõem Cloaca foram instaladas, mais de uma vez, no interior de edifícios góticos, ou ao lado de outra série de trabalhos do 
artista na qual imagens de raios-X do interior do corpo são transformadas em vitrais góticos. As relações entre ciência e religião são, hoje, muito mais complexas do que poderíamos vislumbrar através de um dualismo opositivo. A crença, a fé, as demandas de proteção contra o sofrimento parecem ser endereçadas igualmente a ambos os domínios.

Valentin Nussbaum (2008) propôs uma leitura do conjunto da obra de Wim Delvoye a partir do conceito de sagrado, cartografando uma série de referências religiosas que atravessam vários projetos do artista belga. No que diz respeito à Cloaca, o autor escreve:

No quadro específico de uma máquina que produz merda, a evocação do sagrado poderia seguramente passar por uma contradição absoluta. Mas se sabemos que o artista projeta instalar esse tipo de máquinas - que ele qualifica de "novo Deus" - em capelas góticas, à imagem da que já existe em Nova York, a analogia torna-se mais pertinente (NUSSBAUM, 2008, p. 83).

A instalação de Cloaca no interior de edifícios góticos pode ser mais bem compreendida se retomamos as relações do artista com a religião católica, da qual ele pôde viver os rituais em sua infância. Por um lado, a religião (como o marketing) transforma-se em uma linguagem para o Delvoye adulto, que chega a conceber um "kit religião, como há os kits design, com suas igrejas, seus hinos, suas liturgias" (DELVOYE, 2007 in NUSSBAUM, 2008, p. 84). Por outro, algumas das práticas religiosas vistas pelo artista durante sua infância permanecem uma fonte de assombro.

Quando Delvoye se lembra das velhas mulheres de sua infância que beijam os pés das estátuas ou que viram a estátua de Santo Antônio de cabeça pra baixo quando perdem uma tesoura, não é somente a perplexidade de uma criança que se exprime diante da estranheza intrínseca a essas práticas dogmáticas, e até mesmo idólatras. É também uma interrogação que se coloca diante de fenômenos cultuais paradoxais e surpreendentes em mais de um sentido (NUSSBAUM, 2008, p. 84). 
A inscrição de uma dimensão sagrada e preciosa sobre "despojos algumas vezes repulsivos” (NUSSBAUM, 2008, p. 85) produz uma lacuna que vai justamente nutrir a pesquisa do artista a respeito da mise-en-scène desses objetos extremamente discretos e triviais que se tornam alvo de adoração e veículo de transcendência.

Em um sentido, a problemática ligada às máquinas Cloaca de Wim Delvoye não está muito distante desta questão. Quando os superlativos são empregados para qualificar essas máquinas que produzem abjeções vendidas como um bem dos mais preciosos e sobre as quais pode-se especular como um objeto de arte, há um enorme paradoxo colocado. Se consideramos paralelamente o culto das relíquias, sua ostentação e sua reunião como a infância dos princípios que regerão alguns séculos mais tarde a valorização dos objetos de arte nas coleções e a especulação da qual eles são objeto atualmente, parece que a economia e a dinâmica de Cloaca é comparável a uma verdadeira fábrica de relíquias (NUSSBAUM, 2008, p. 85).

Se seguimos o pensamento de Simondon a respeito da gênese dos modos técnico, estético e religioso de existência, Cloaca nos coloca diante de um problema. Isto porque no projeto de Delvoye os dois modos - técnico e religioso - coabitam a máquina que, além disso, é objeto estético. A defecação tecnicamente mediada implica efetivamente um processo de objetivação, tal como postulado por Simondon após a ruptura da unidade originária do mundo. Mas Cloaca, na sua inserção no espaço de instituições artísticas, inscreve-se no sagrado, seja porque a configuração canônica do dispositivo de exposição contemporâneo - o cubo branco - cria um contexto análogo ao de outros locais de culto (O'DOHERTY, 2012); seja porque o artista opta deliberadamente por expor suas máquinas em catedrais góticas ou ao lado de obras que lançam mão de um repertório visual religioso.

Delvoye aproxima o objeto técnico e o objeto religioso de modo que podemos explorar, sincrônica e especulativamente, os limites dos modos de existência que emergem nas formulações de Simondon acerca da gênese da tecnicidade. Esses limites encontram-se, sobretudo, na 
separação entre as duas fases - técnica e religião -, que passam, hoje, por inúmeras inflexões, mediadas pela cultura, pela arte e pela política. Se podemos aventar a hipótese de que Cloaca é também um objeto estético é porque, tensionando técnica e religião, a máquina de merda talvez nos lembre, por contraste, do momento em que todas essas clivagens ainda não existiam.

\section{0 fluxo e o corte}

O anti-Édipo, de Gilles Deleuze e Félix Guattari, fundamenta um importante eixo de nossa análise, a despeito das críticas contundentes que faz à teoria freudiana, evocada mais de uma vez no escopo deste artigo. O desenvolvimento do conceito de máquina foi fundamental para a proposição dos autores franceses de um modo de operação do desejo, através da qual puseram sob suspeita a triangulação edipiana, estrutura do psiquismo cara a Freud, a partir da qual o desejo foi postulado fundamentalmente como falta.

Isso funciona em todos os lugares, às vezes sem parar, às vezes descontínuo. Isso respira, isso esquenta, isso come. Isso caga, isso fode. Que erro ter dito o isso. Por todos os lados são as máquinas, não metaforicamente: máquinas de máquinas, com seus acoplamentos, suas conexões. Uma máquina-órgão é conectada a uma máquina-fonte: uma emite o fluxo que a outra corta (DELEUZE; GUATTARI, 1972, p. 9, grifo dos autores).

Esta proposição apresenta duas consequências que nos interessa explorar. A primeira é pertinente à nossa análise de Cloaca, mas poderia igualmente servir a uma reflexão mais ampla acerca do estatuto do consumo. Isto porque ela deriva da onipresença de máquinas (máquinas-fonte e máquinas-órgão) a impossibilidade de preservar as clivagens que separam produção e consumo como circuitos autônomos e relativamente independentes. "Porque na verdade [...] não há esferas ou circuitos relativamente independentes: a produção é imediatamente consumo e inscrição, a inscrição e o consumo determinam 
diretamente a produção, mas a determinam no seio da própria produção" (DELEUZE; GUATTARI, 1972, p. 11).

Cloaca parece tornar-se um lugar privilegiado para verificarmos o primado da produção ou, dito de outro modo, o fato de que a inscrição e o consumo não são exteriores e/ou posteriores à produção. $\mathrm{O}$ consumo das refeições pelas máquinas Cloaca já é produção de outro fluxo: o fluxo de merda. As máquinas de Delvoye permitem ver, de modo bem esquemático, o que Deleuze e Guattari chamaram de lei de produção de produção. Não por acaso, o artista investiu no mesmo topos que alimentou a dupla de filósofos: a digestão.

A máquina produz um corte no fluxo somente se estiver conectada a uma outra máquina que produza o fluxo. E sem dúvida essa outra máquina é, por sua vez, um corte. Mas ela não o é senão em relação a uma terceira máquina que produziu idealmente, ou seja, relativamente, um fluxo contínuo infinito. Assim, a máquina-ânus e a máquina-intestino, a máquina-intestino e a máquina-estômago, a máquina-estômago e a máquina-boca, a máquina boca e o fluxo do rebanho (“e, e, e...”). Em suma, toda máquina é corte de fluxo em relação àquela a qual ela está conectada, mas fluxo ou produção de fluxo em relação àquela que lhe está conectada (DELEUZE; GUATTARI, 1972, p. 46).

A máquina de máquinas de Delvoye reverbera algumas das instigantes concepções de mundo e de desejo formuladas por Deleuze e Guattari. Primeiramente por sua dimensão literalmente maquínica; mas também por duas outras dimensões que são pensadas pelos filósofos como fábrica: a natureza e o inconsciente. Não há, em $O$ anti-Édipo, distinção entre o homem e a natureza. O desejo torna-se um princípio imanente nas relações de produção que ligam o homem à natureza - o homem, máquina-órgão conectado à natureza, máquina-fluxo ou máquina-energia. O segundo âmbito concebido como fábrica é o inconsciente, que deixa de engendrar representações para se tornar agenciamento maquínico e, portanto, corte e produção de fluxos.

Esta aposta na produtividade imanente da máquina desejante coloca em xeque as análises mais niilistas de Cloaca. A perspectiva do moralista 
que reduz a consumismo o fato de que a merda produzida pelas máquinas de Delvoye esteja disponível para venda torna-se insustentável diante de uma retomada da crítica de Deleuze e Guattari à divisão platônica que separa produção e aquisição. O desejo, pensado nesta chave, só poderia (1) ter por objeto algo engendrado por um sujeito-produtor ou (2) ser projetado sobre um objeto que falta e que seria necessário adquirir. A questão que permanece aberta consiste em saber se, no caso da aquisição da merda produzida por Cloaca, estaríamos diante de um processo de produção ou de consumo. O excremento sintético simboliza uma falta ou sua aquisição nasce de um impulso produtor, como aquele que dá origem às coleções²?

\section{Beijos anais e considerações finais}

É interessante observar como o tema da analidade reaparece em Anal Kisses (Figura 21), projeto de Delvoye de 2011 que não se torna objeto de um debate público, como foi o caso de Cloaca. Em Anal Kisses, a analidade assume uma forma menos espetacular do que em Cloaca, embora mais explícita; mas as relações entre economia, arte e sacralidade reaparecem. A série consiste em um conjunto de intervenções do artista sobre papéis timbrados de hotéis. Como o título indica, trata-se de uma série de impressões de beijos, cuja particularidade está no fato de que em vez de inscrevem as formas dos lábios sobre o papel, é o ânus do artista que é impresso. Apesar dessas imagens do ânus serem figurativas e indiciais, Anal Kisses não gozou da repercussão obtida por Cloaca ao longo dos dez anos anteriores. Questões ligadas à escala do trabalho e à mídia utilizada talvez ajudem a entender porque estes beijos nunca chegaram às primeiras páginas dos jornais. 
Figura 21 - Anal Kiss, 2011, batom sobre papel timbrado.

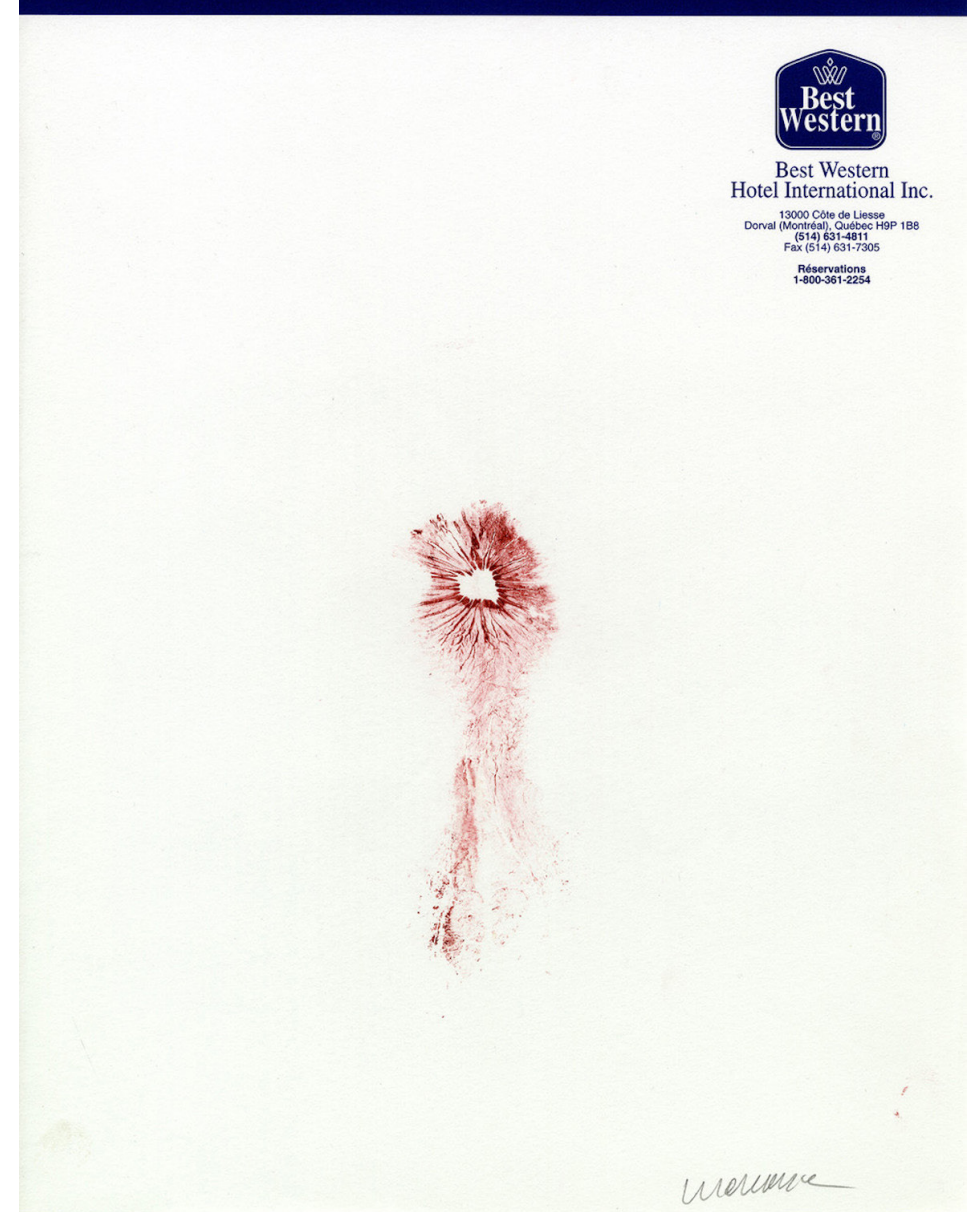

Fonte: <https://bit.ly/2SGCnkm>. Acesso em: 9 abr. 2019.

De todo modo, é interessante observar que na série de 2011 encontramos algumas questões que vinham sendo formuladas em Cloaca. Nos Anal Kisses, as logomarcas reaparecem nos papéis timbrados de hotéis e entram em tensão com as imagens dos beijos anais do artista. A arquitetura impessoal e globalizada dos hotéis é virtualmente inscrita na obra, através do signo institucional que coabita a composição com o beijo anal. Anal Kisses reitera a inexistência de uma exterioridade em relação 
à lógica do consumo, mas parece tentar abrir uma brecha através do reenquadramento do ânus, maquiado como boca. Se Cloaca sublima o ânus no maquinário industrial produtor de merda, Anal Kisses faz coincidir o ânus com a boca, lugar de articulação do logos e, sobretudo, parte do corpo autorizada a se manifestar no espaço público, seja tomando a palavra, seja dando um beijo. Em um esforço de compreensão do tratamento dispensado pela crítica de arte e pela opinião pública a estes projetos artísticos podemos observar que muitos fatores concorrem para que um projeto transborde do sistema da arte para o campo da cultura. É fundamental reconhecer que, para além dos fundamentos estéticos, técnicos e filosóficos que se encontram na base de Cloaca, há toda uma dimensão arquitetural, expográfica, espetacular e, evidentemente, mercadológica, que incide em sua recepção.

A recepção discreta dos Anal Kisses poderia indicar, comparativamente, um maior potencial disruptivo na merda sintética de Cloaca do que na refuncionalização de um ânus que beija. Mas iremos apostar que este contexto apenas fornece algumas pistas acerca da complexidade histórica, cultural e midiática, e da heterogeneidade de fatores que hoje incidem sobre a experiência e a crítica da arte. Custos de produção, prestígio institucional e instagramabilidade de obras de arte reverberam na experiência estética, juntamente com os sedimentos que constituem o solo de nossa cultura - dentre eles, a estranha coexistência de tecnofilia e tecnofobia em nossa relação com a técnica; o banimento do merda e do cu da vida social; a artificialidade da clivagem entre produção e consumo.

\section{Referências}

BATAILLE, G. CEuvres complètes I: Premiers Écrits 1922-1940. Paris: Gallimard, 1970. BELO, F. R. R.; MARZAGAO, L. R. Avareza e perdularismo. Psyche, São Paulo, v. 10, n. 19, p. 109-128, 2006.

DELEUZE, G.; GUATTARI, F. L'anti-CEdipe: Capitalisme et schizophrénie I. Paris: Les Éditions de Minuit, 1972. 
FREUD, S. Malaise dans la civilisation. Revue Française de Psychanalyse, v. 7, n. 4, p. 692-769, 1934.

. Sur les transformations des pulsions particulièrement dans l'érotisme anal. Revue Française de Psychanalyse, v. 2, n. 4, p. 609-616, 1928.

KRISTEVA, J. Powers of Horror: An Essay on Abjection. Nova York: Columbia University Press, 1982.

LAPORTE, D. History of Shit. Boston: Massachusetts Institute of Technology e Documents Magazine, 2000.

NUSSBAUM, V. Wim et la sacrée reliquerie. Enfance de l'art et reliques du sacré dans l'œuvre de Delvoye. kritische bericht, n. 3, p. 83-92, 2008.

O'DOHERTY, B. Inside the White Cube: L'ideologia dello spazio espositivo. Monza: Johan \& Levi Editore, 2012.

PATTERSON, K. Blending science, art and other excremento. The Conversation, 11 fev. 2016. Disponível em: https://bit.ly/2GsvHjk. Acesso em: 15 fev. 2019.

PROSS, H. Estructura simbólica del poder. Barcelona: Editorial Gustavo Gili S.A., 1980. RANCIÈRE, J. The Emancipated Spectator. Londres, Nova York: Verso, 2009.

SIMONDON, G. Du mode d'existence des objets techniques. Paris: Aubier, 1989.

WALLACE, I. L. Deep Shit: Thoughts on Wim Delvoye's Cloaca Project. In: Contemporary Art and Classical Myth.

WALLACE, I. L.; HIRSH, J. (Orgs.). Contemporary Art and Classical Myth. Surrey: Ashgate, 2011.

\section{Sobre o autor}

Icaro Ferraz Vidal Junior - Doutor em História, História da Arte e Arqueologia pelas Université de Perpignan Via Domitia e Università degli studi di Bergamo e em Comunicação e Cultura pela Universidade Federal do Rio de Janeiro. Realizou estágio pós-doutoral no Programa de Pós-Graduação em Comunicação e Linguagens da Universidade Tuiuti do Paraná. Atualmente é bolsista de pós-doutorado PNPD-Capes no Programa de Estudos Pós-Graduados em Comunicação e Semiótica da Pontifícia Universidade Católica de São Paulo.

Data de submissão: 09/04/2019

Data de aceite: 04/10/2019 